\title{
Multi-instrument study of footprints of magnetopause reconnection in the summer ionosphere
}

\author{
S. E. Pryse, A. M. Smith, I. K. Walker, L. Kersley \\ Department of Physics, University of Wales, Aberystwyth, Ceredigion SY23 3BZ, UK
}

Received: 10 January 2000 / Revised: 17 April 2000 / Accepted: 18 April 2000

\begin{abstract}
Results are presented from a multi-instrument investigation of the signatures of equatorial reconnection in the summer, sunlit ionosphere. Well-established ion dispersion signatures measured during three DMSP satellite passes were used to identify footprints in ionospheric observations made by radio tomography, and both the EISCAT ESR and mainland radars. Under the prevalent conditions of southward IMF with the $B z$ component increasing in magnitude, the reconnection footprint was seen to move equatorward through the ESR field-of-view. The most striking signature was in the electron temperatures of the F2 region measured by the EISCAT mainland radar that revealed significantly enhanced temperatures with a steep equatorward edge, in general agreement with the leading edge of the ion dispersion. It is suggested that this sharp transition in the electron temperature may be an indicator of the boundary, mapping from the reconnection site, between closed geomagnetic field lines and those opened along which magnetosheath ions precipitate.
\end{abstract}

Key words: Ionosphere (ionosphere-magnetosphere interactions; particle precipitation; plasma temperature and density)

\section{Introduction}

Magnetic reconnection was proposed by Dungey (1961) as the key coupling process between the interplanetary magnetic field and the geomagnetic field. With a southward orientation of the IMF, reconnection is likely near the equatorial plane and the newly opened field-lines are swept antisunward. For strongly positive

Correspondence to: $\mathrm{S}$. E. Pryse
$B z$, the field merging is preferentially in the magnetospheric lobe, and the opened field lines initially move sunward. These magnetospheric processes can extend over very large volumes of space but their signatures are brought into close proximity when they are mapped down the converging geomagnetic field into the vicinity of the cusp. Equatorial reconnection drives a two-cell high-latitude convective flow, comprising antisunward cross-polar flow and return sunward flows at lower latitudes in the dawn and dusk sectors (Reiff and Burch, 1985; Cowley, 1998). By contrast, lobe reconnection is thought to generate a pair of lobe convection cells with sunward cross-polar flow. Tension forces caused by the IMF $B y$ component distort the symmetry of the convection cells, displacing the polar flow from the solar meridian (Cowley et al., 1991). Signatures of the velocity filter dispersion (Rosenbauer et al., 1975), in energy flux measurements of precipitating ions by low-altitude satellites (Newell and Meng, 1995), are characteristic of reconnection. The fastest particles arrive first along newly opened field-lines, with the less energetic ions being found subsequently when the opened field-lines have convected downstream with the plasma. For southward IMF, with antisunward flow in the polar cap, the lower energy ions are found poleward of the dispersion high-energy edge, but in lobe reconnection the dispersion signature is reversed in the sunward convection. The energy deposition of cusp precipitation with particle fluxes of energy less than a few hundred $\mathrm{eV}$ produces enhancements in F-region electron temperature (Nilsson et al., 1994). Optical observations allowed Sandholt et al. (1998) to divide auroral activity in the cusp into three main configurations, depending on the IMF clock angle. Type 1 aurora occur at typically $70^{\circ}$ to $74^{\circ}$ MLAT under the conditions of equatorial reconnection, with clock angles between $90^{\circ}$ and $180^{\circ}$. Type 2 aurora are found at $\sim 78^{\circ}-79^{\circ}$ MLAT under strongly northward IMF conditions, when the clock angle is in the range $0^{\circ}$ to $45^{\circ}$. There is a coexistence of type 1 and type 2 auroral forms for clock angles between $45^{\circ}$ and $90^{\circ}$. Footprint signatures of reconnection processes in the spatial 
distribution of the ionospheric plasma density were reported by Walker et al. (1998) and Pryse et al. (1999) for $B z$ negative and positive respectively. The former study identified a density enhancement co-located with type 1 aurora, with a steep density gradient on its equatorward side. A tilt in the $\mathrm{F}$ layer peak height was found with the altitude of maximum density increasing with latitude in keeping with the softening ion precipitation. The latter companion paper for steady, northward IMF revealed the reverse dispersion signature, with the height of the $\mathrm{F}$ region peak increasing with decreasing latitude. The structure was bounded on its equatorward edge by a footprint of the adiaroic wall across which no plasma flows. In a subsequent multiinstrument study, it was found that the EISCAT Svalbard radar showed evidence of increased electron temperatures within the region of ion dispersion (Pryse et al., 2000).

Identification of ionospheric plasma signatures of reconnection has relied heavily to date on comparisons with optical auroral forms. Of necessity the observations were for the dark winter months of the polar ionosphere under a clear sky. The current work uses observations from many instruments to identify footprints of equatorial reconnection in the plasma during summer daylight. Measurements by particle detectors aboard satellites, radio tomography, and both incoherent and coherent scatter radars are presented, from experiments made in the magnetic noon sector on 20 August, 1998.

\section{Observations}

\subsection{Interplanetary magnetic field}

The three components of the IMF measured upstream in the solar wind by the ACE satellite between 0700 and 0900 UT are shown in the three panels of Fig. 1. The estimated delay between the observations and ionospheric response is about 70 min (Lockwood et al., 1989). Of particular relevance is the relatively strong negative $B z$ component, initially steady at approximately $-7 \mathrm{nT}$, but increasing gradually in magnitude after about 0730 UT and then more abruptly around 0800 UT to reach some $-12 \mathrm{nT}$. In comparison, both the $B x$ and $B y$ components were relatively weak, with the former being positive and the latter mainly negative though with two positive excursions at the time of the decrease in $B z$ at around 0800 UT.

\subsection{Plasma convection}

The Finland SuperDARN radar (CUTLASS) measured line-of-sight plasma velocities that were relatively constant throughout the time interval of interest. Figure 2 for $0842: 45$ UT is representative of the period. The velocities show antisunward flow in the polar region
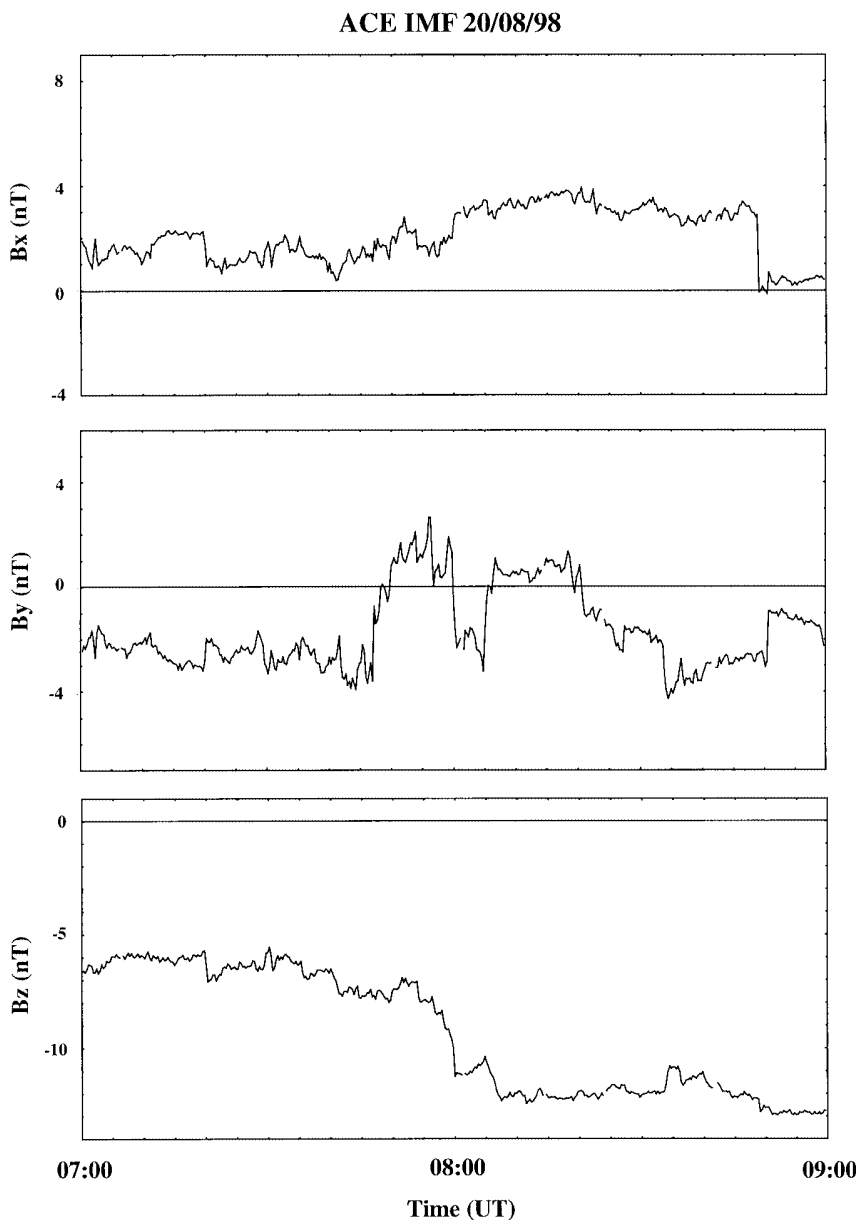

Fig. 1. $B x, B y$ and $B z$ components of the Interplanetary Magnetic Field intensity measured by the ACE satellite upstream in the solar wind between 0700 and 0900 UT on 20 August, 1998

north of Svalbard, as expected for the negative $B z$. In addition, there are hints of flow toward the radar at the edges of the field-of-view in-keeping with sunward return flows at lower latitudes.

\subsection{DMSP}

Three DMSP satellite passes traversed the noon-sector polar cap during the time interval of interest. Each set of observations showed clear signatures of ion dispersion with a sharp low-latitude cut-off of the incoming particle flux. The electron and ion flux spectra for the pass of satellite F14 around 0853 UT are shown in Fig. 3, where the equatorward edge for the ion dispersion can be identified at 73.5 MLAT and 1240 MLT. Similar dispersion signatures were revealed in two other satellite passes at 0832 and 1038 UT, with the MLT extent of the signatures depending on the geometry of the satellite trajectory. The dispersion signatures for each of the passes are illustrated in the MLAT/MLT plot of Fig. 4 as triangular shapes where the base line indicates the cut-off of the high-energy ions at the open/closed 


\section{SUPERDARN PARAMETER PLOT}

Finland: vel

\section{Aug $1998^{\text {(232) }}$}

unknown scan mode (-6315)

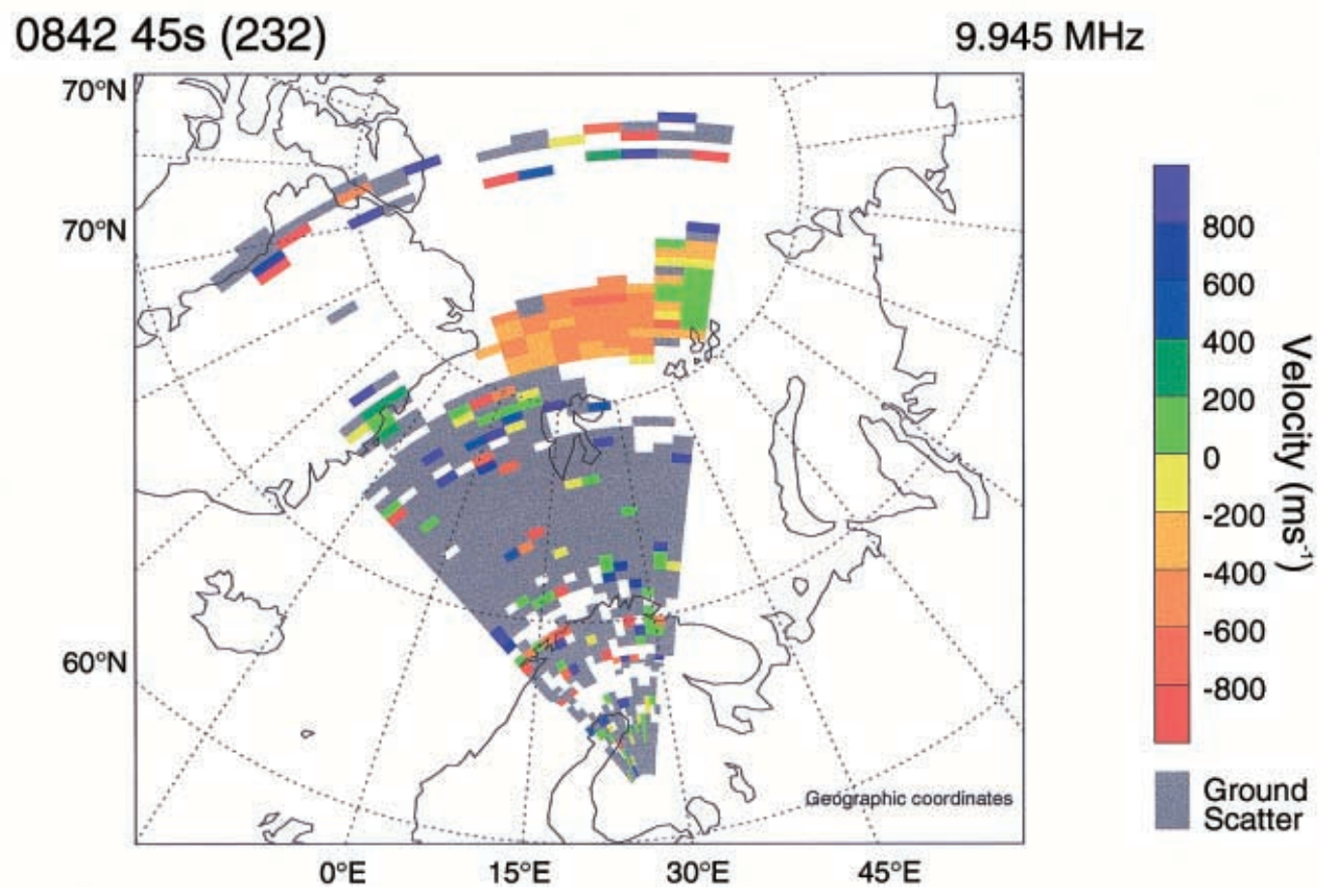

Fig. 2. Line-of-sight velocities measured by the Finland radar of the CUTLASS SuperDARN facility at 0842:45 UT on a geographic grid. Positive values represent flows towards the radar and negative values flows away from the radar

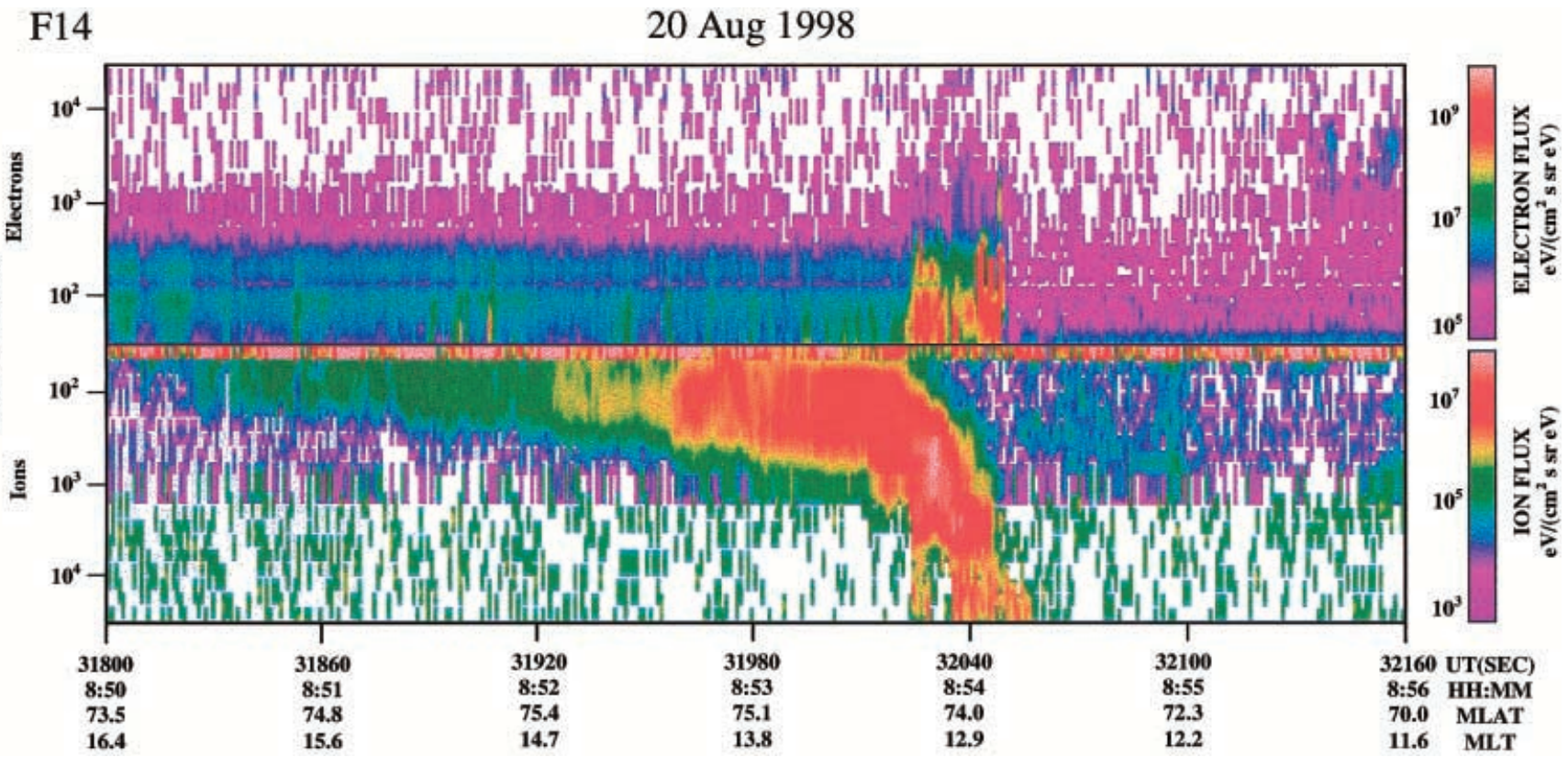

Fig. 3. Electron and ion flux spectra for the pass of the DMSP F14 satellite at around 0853 UT. The energy scales are in the opposite senses for the two panels, with the electron energies being largest at the top of the electron flux panel but the ion energies largest at the bottom of the ion flux panel

\subsection{Radio tomography}

A radio tomography satellite in the NIMS constellation (Navy Ionospheric Monitoring System) that crossed a tail of the lower-energy incoming ions observed along the satellite trajectory. An equatorward progression of the boundary can be seen. 


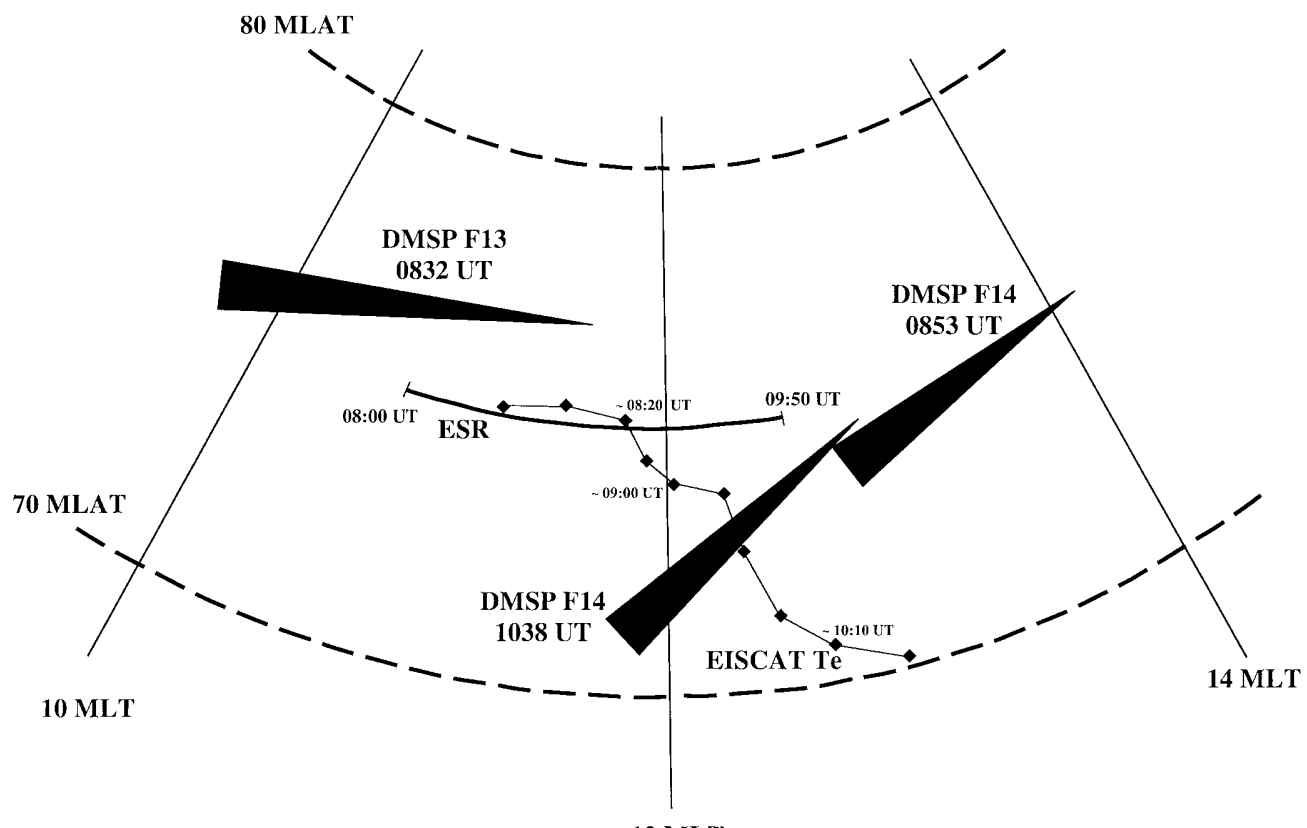

12 MLT
Fig. 4. Plot showing the mapping of the observations on a geomagnetic latitude versus MLT grid. The locations of the ion dispersion signatures measured during the three DMSP satellite passes at 0832,0853 and 1038 UT are shown by the black triangles. The base of the triangles indicates the high-energy cut-off of the signatures and the apex the extent of the tail of softer precipitation. Also shown is the intersection at $300 \mathrm{~km}$ of the ESR radar beam between 0800 and 0950 UT. The progression of the position of the equatorward edge of the region of elevated electron temperatures measured by the EISCAT mainland radar during OMOT observations between 0720 and 1030 UT is also marked

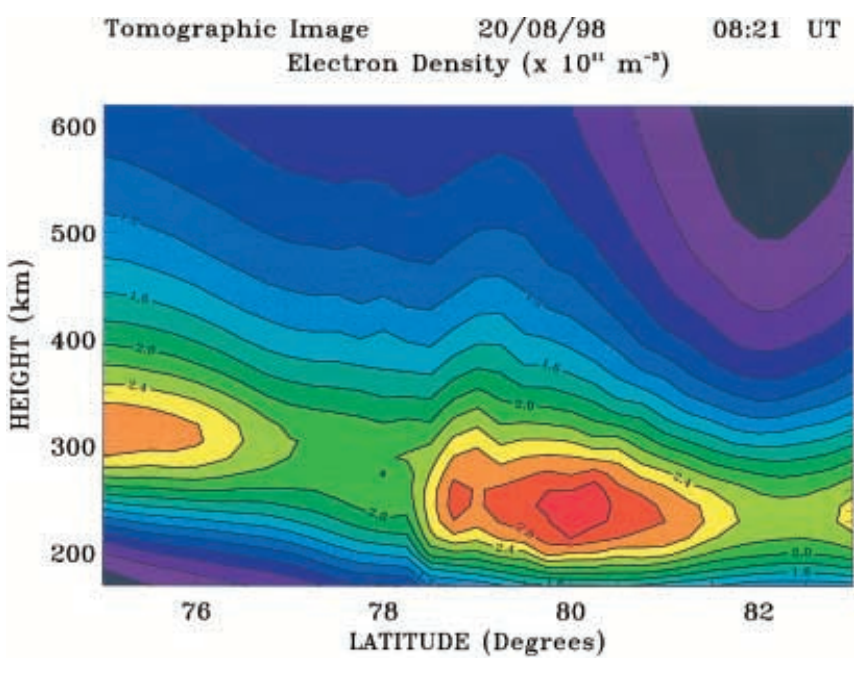

Fig. 5. Tomographic reconstruction of the spatial distribution of ionospheric electron density measured during a NIMS satellite pass that crossed $75^{\circ} \mathrm{N}$ at $0821 \mathrm{UT}$

latitude of $75^{\circ} \mathrm{N}$ at 0821 UT yielded the broad structure of the spatial density distribution of ionospheric plasma shown in Fig. 5, where the image plane maps to approximately $1050 \mathrm{MLT}$ at $75^{\circ} \mathrm{N}$. In the southern region of the field-of-view the increasing effect of solarproduction with decreasing latitude is seen in what is essentially a summer mid-latitude ionosphere. However, north of $78^{\circ} \mathrm{N}$ there is a density enhancement separated from the ionosphere to the south by a density trough. The location of the region of elevated density was to the north of the most northerly tomography receiver so that the finer details of the plasma density signatures of reconnection are not resolved, though the steeper gradient on the equatorward edge of the feature can be identified (Walker et al., 1998).

\subsection{EISCAT Svalbard radar}

The EISCAT Svalbard incoherent scatter radar $\left(78.2^{\circ} \mathrm{N}\right)$ was operating as part of the OMOT UK Special Programme experiment with the radar pointing along the geomagnetic field in the $\mathrm{F}$ region. The viewing region of the EISCAT Svalbard radar (ESR) is illustrated in Fig. 4 where the intersection of the radar beam with an altitude of $300 \mathrm{~km}$ is shown between 0800 and 0950 UT. The DMSP ion dispersion signatures around 0832 UT were north of the ESR intersection latitude of about $75^{\circ} \operatorname{MLAT}\left(77.8^{\circ} \mathrm{N}\right)$ but to the south by 1038 UT. Comparison with Fig. 5 shows that the plasma enhancement in the tomographic image was north of the ESR field-of-view at around 0821 UT.

The upper and lower panels of Fig. 6 show the electron density and electron temperature respectively, measured by the ESR radar between 0800 and 0950 UT and analysed using a post-integration time interval of $30 \mathrm{~s}$. At the beginning of the time of interest, when the DMSP dispersion signature and tomography density enhancement were north of the radar viewing region, the densities and electron temperatures observed by ESR were low. However, at about 0837 UT there was an abrupt onset of increased values in both parameters that can be attributed to the precipitation region moving equatorward and coming into the field-of-view of the radar in response to the increasingly negative $B z$. It can be noted that during the period of enhanced densities and temperatures lasting until about 0930 UT there are variations in both parameters on time scales of a few minutes, though a detailed discussion of this fine structure is beyond the scope of the present study. The densities and temperatures reverted to near former background levels after about 0930 UT with contours rising to greater altitudes in the bottomside. The return 

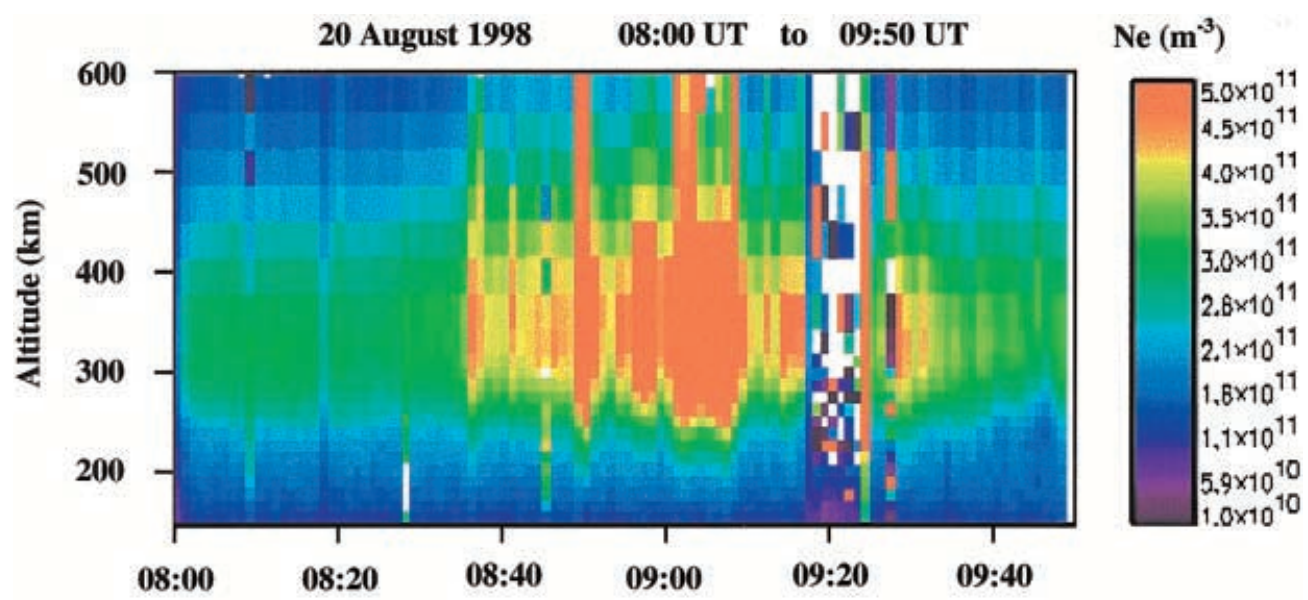

$\mathrm{Te}(\mathrm{K})$

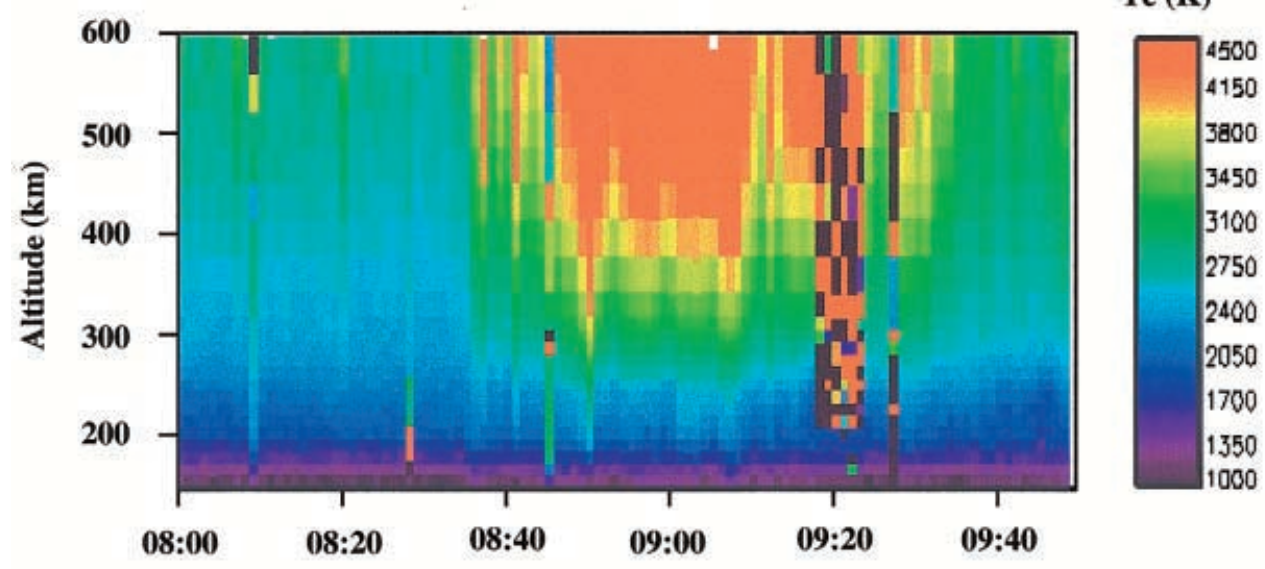

Time (UT)
Fig. 6. Electron densities (upper panel) and electron temperatures (lower panel) measured by the ESR radar between 0800 and 0950 UT observing with the beam aligned along the geomagnetic field in the $\mathrm{F}$ region. These measurements were degraded by interference for a few minutes around 0920 UT to background levels can be interpreted as being linked to the precipitation region associated with the ion dispersion having moved further to the south, out of the ESR field-of-view.

\subsection{EISCAT mainland radar}

The most striking effect of the southward progression of the reconnection signature can be seen in the electron temperatures observed by the EISCAT mainland radar $\left(69.6^{\circ} \mathrm{N}\right)$ which was also observing in the OMOT UK Special Programme mode, scanning in the geographic meridian in cycles of 20 min duration. In each cycle, the radar started pointing in the zenith, and then scanned northward in latitudinal steps of $0.125^{\circ}$ at $300 \mathrm{~km}$ with a dwell time of $20 \mathrm{~s}$ at each pointing direction. The electron temperatures measured between 0800 and 1030 UT are shown in the sequence of panels in Fig. 7. The first plot contains a hint of increased temperatures at the extremity of the field-of-view. These furthest range gates in the most northerly pointing directions represent returns from the topside ionosphere to the north of the ESR field-of-view. The region of elevated electron temperatures moved progressively to lower latitudes with time, with the sharpness of the equatorial edge becoming increasingly apparent as the feature came into the centre of the viewing area. The latitudinal movement of the equatorward edge, defined at an electron temperature of $3500 \mathrm{~K}$ and mapped down field lines to an altitude of $350 \mathrm{~km}$, is also plotted in geomagnetic terms in Fig. 4. A gradual southward motion of the gradient is seen to start at about 0820 UT, with the progression becoming more rapid at about 0915 UT. While it is not possible to be precise about the exact timing, because of the 20 min cycle time of the EISCAT scans, it is likely that the relatively slow latitudinal motion occurred in response to the gradually increasingly-negative $B z$ measured in the IMF, and that the more rapid motion was linked to the later sharper change in $\mathrm{Bz}$. It is also of note that the motion of the equatorward edge of the elevated temperatures is in general agreement with the equatorward edge of the dispersion signatures observed by the second and third DMSP satellite passes.

The electron densities measured by the scans between 0800 and 0920 UT, though not shown here, revealed only the characteristics of solar-controlled $\mathrm{F}$ layer plasma with a peak height at about $300 \mathrm{~km}$. The absence of footprints of the reconnection process is not surprising as the precipitation, apparent in the elevated electron temperatures at higher altitudes, maps to the $\mathrm{F}$ region at latitudes north of the viewing volume. 

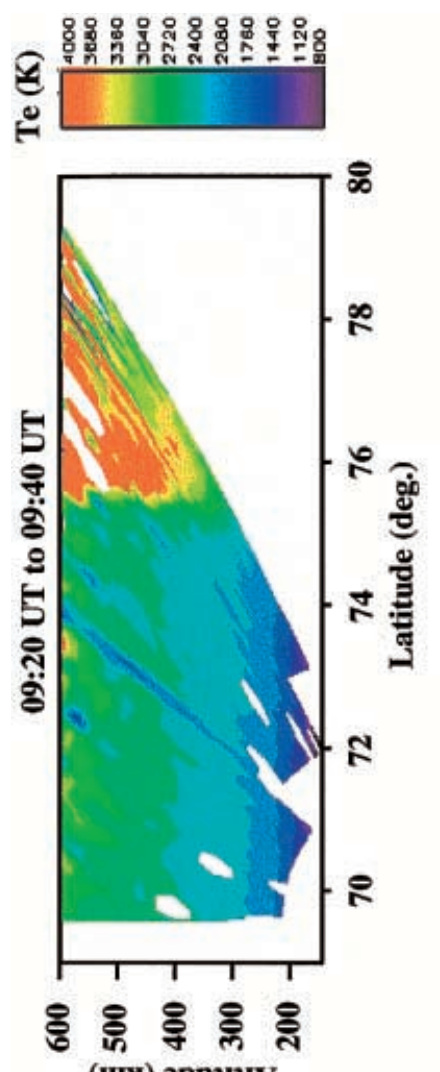

(uxy) әpm!!
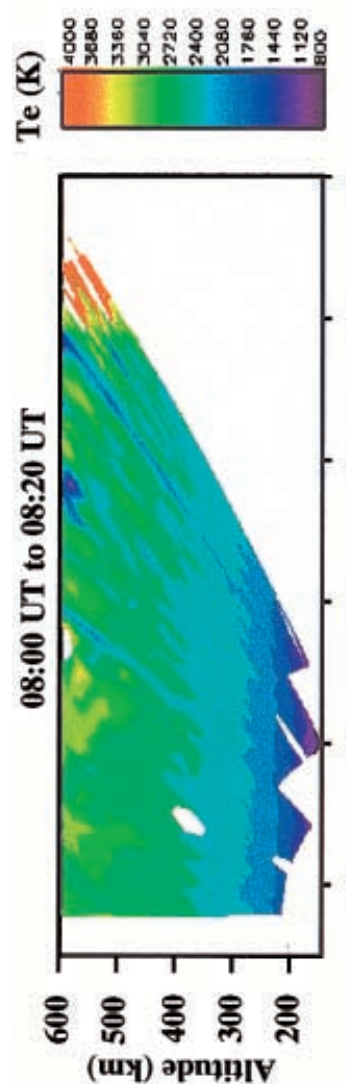
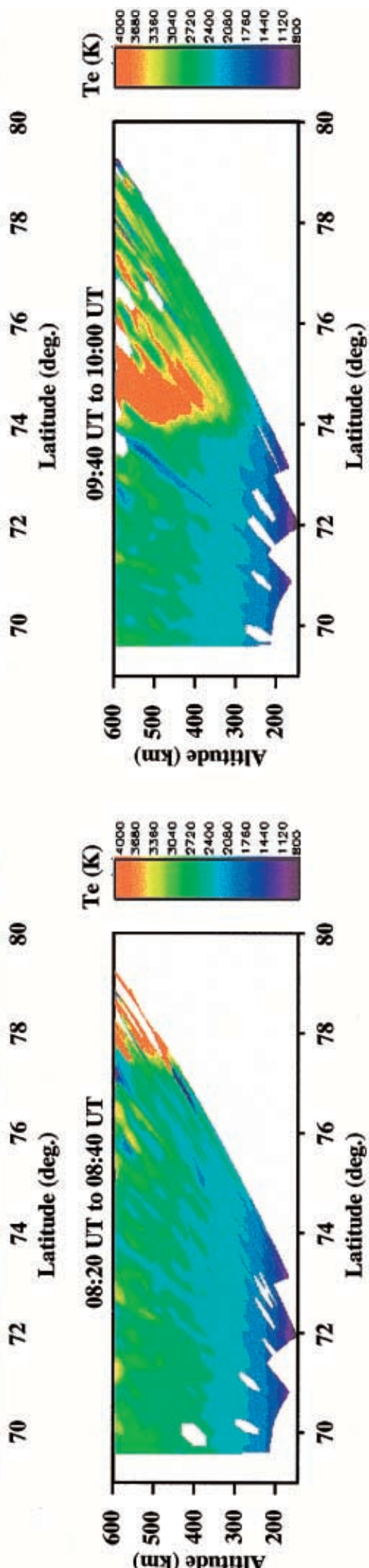
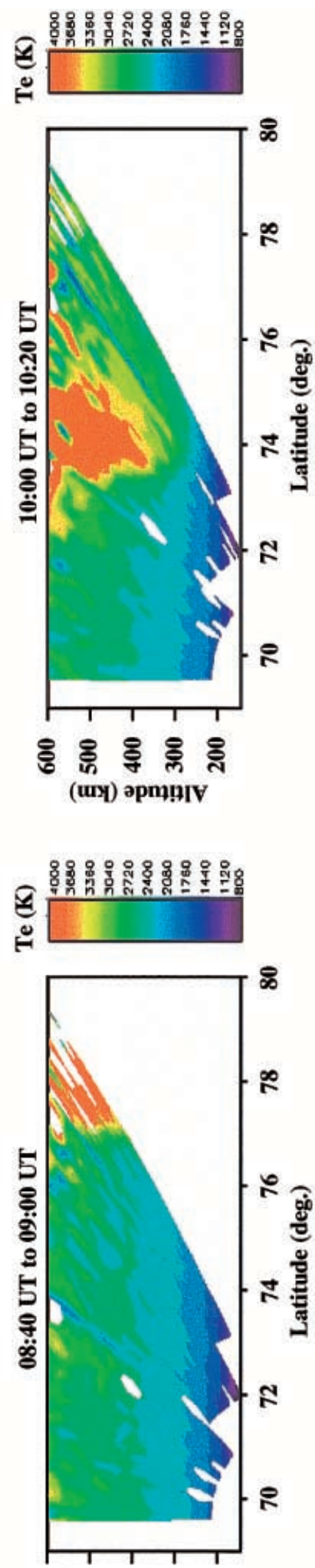

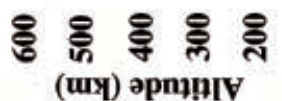
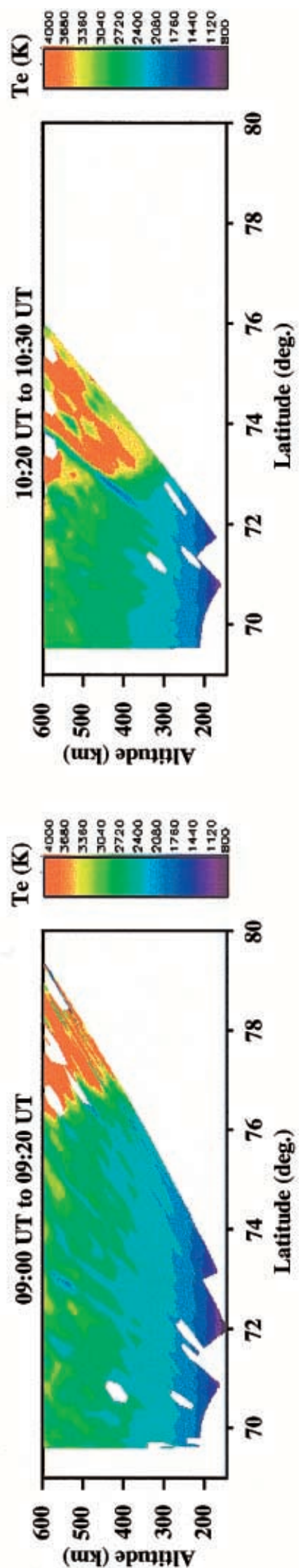

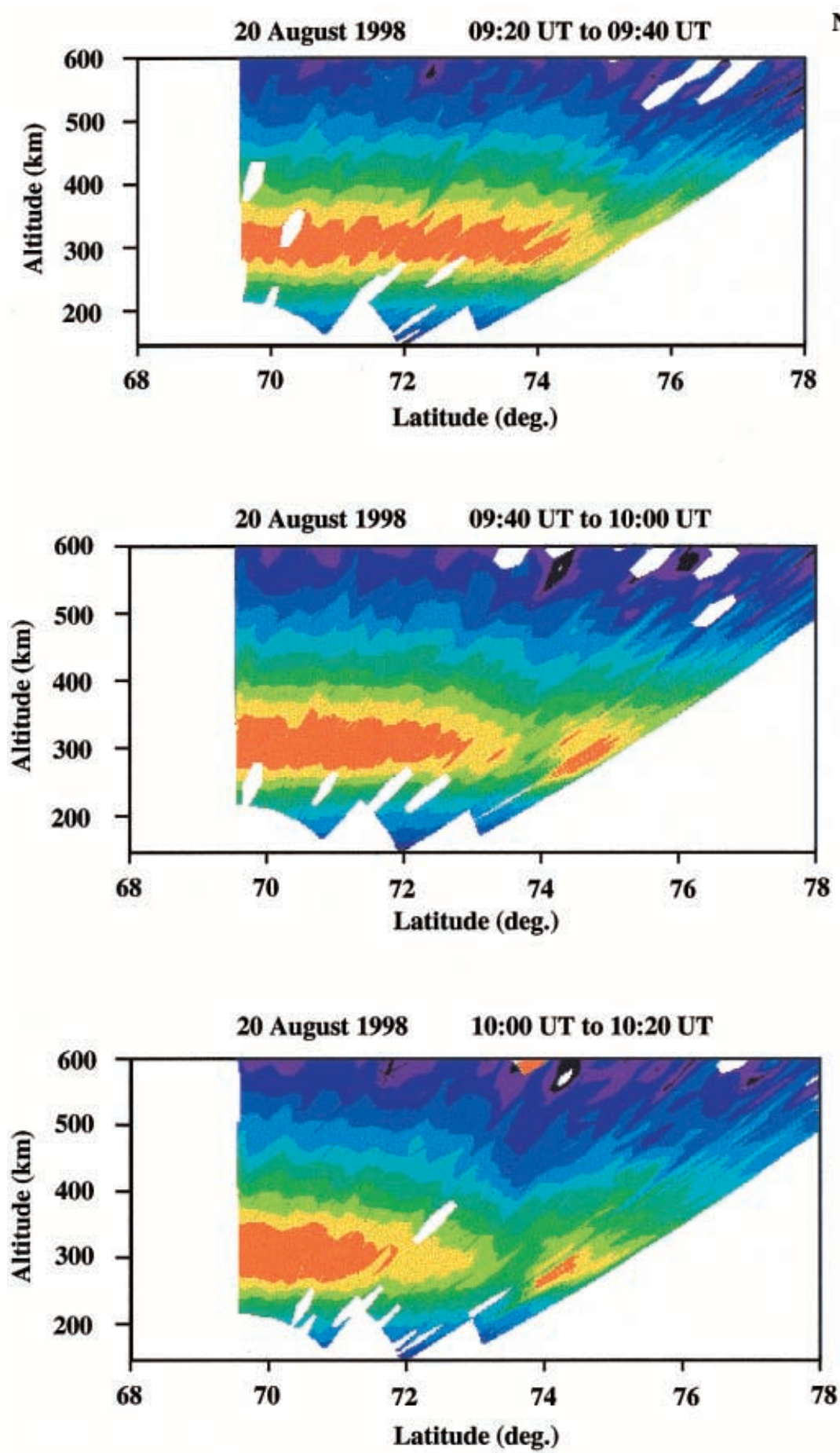

$\mathrm{Ne}\left(\mathrm{m}^{-3}\right)$

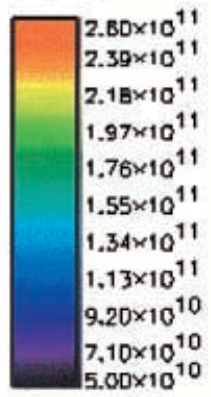

$\mathrm{Ne}\left(\mathrm{m}^{-3}\right)$

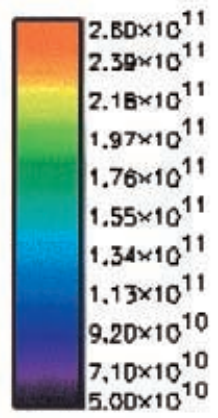

$\mathrm{Ne}\left(\mathrm{m}^{-3}\right)$

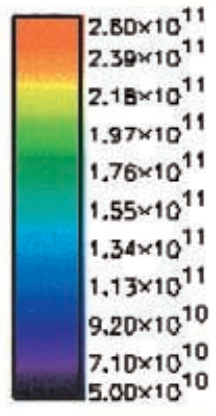

Fig. 8. Electron densities measured by the EISCAT mainland radar observing in the OMOT UK Special Programme mode for the scans between 0920 and 1020 UT
However, structure is observed near the layer peak at the northern extremity of the scan starting at $0920 \mathrm{UT}$, and this can be seen to move progressively southward in the following plots (Fig. 8). Close inspection of the bottom panel, for the scan starting at 1000 UT, shows that the densities in the enhancement in the north

Fig. 7. Electron temperatures measured by the EISCAT mainland radar observing in the OMOT UK Special Programme mode between 0800 and 1030 UT exceeded those of the solar-ionisation at latitudes to its south. In addition, the altitude of the layer peak within the enhancement was marginally lower than that of the solar-produced plasma. These characteristics of the enhancement, and its co-location with the elevated electron temperatures at the F-peak altitude, suggest that some of the ionisation originated from the soft precipitation and that it formed at the equatorward edge of the ion dispersion signature of the reconnection. However, it must be noted that this precipitationproduced ionisation constitutes only part of the total 


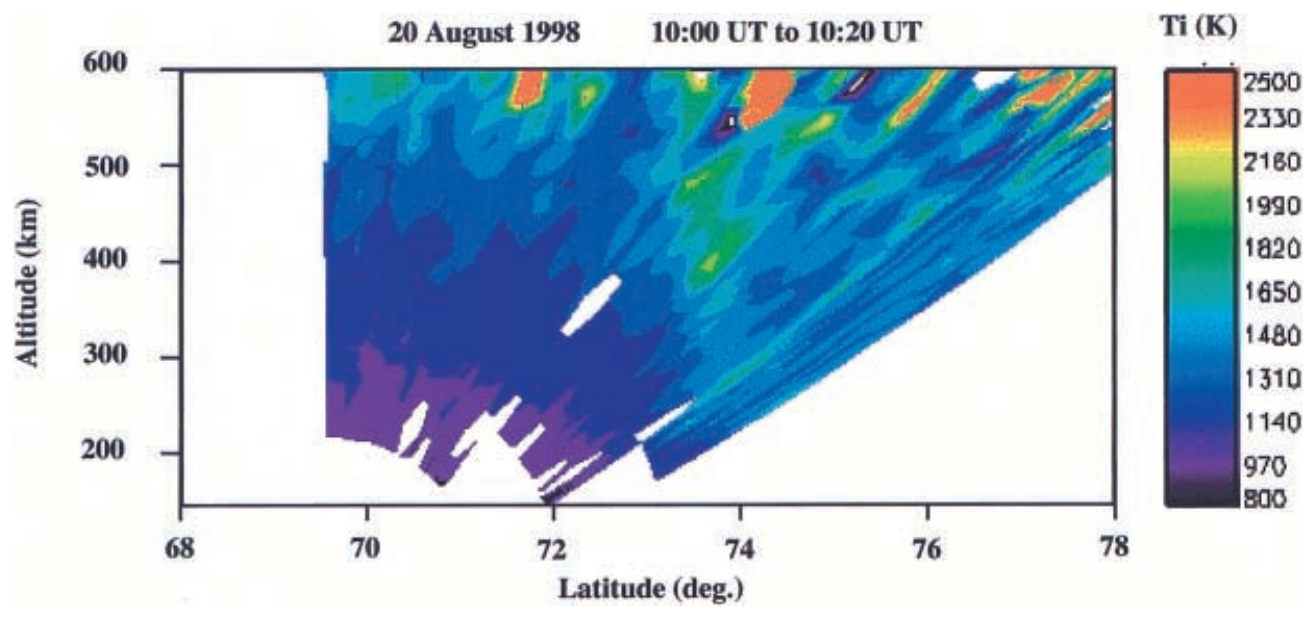

Fig. 9. Ion temperatures measured by the EISCAT mainland radar observing in the OMOT UK Special Programme mode during the scan starting at $1000 \mathrm{UT}$ density within the enhancement, with solar radiation also playing an important role in the sunlit summer ionosphere.

The density trough separating the enhanced density structure to the north and the strictly solar-produced ionosphere to the south can be related to a region of elevated ion temperatures. It can be seen from the scan starting at 1000 UT, shown in Fig. 9, that a field-aligned region of higher ion temperatures at altitudes above the F-region peak is located between $73.5^{\circ}$ and $74.0^{\circ} \mathrm{N}$. It is also of note that EISCAT tristatic westward velocities measured in this region were found to be in excess of $1 \mathrm{~km} \mathrm{~s}^{-1}$. The narrow trough in electron density was thus likely to be a consequence of ion frictional heating resulting in an enhanced loss rate. Comparing the electron densities at the peak, it can be seen that a depletion of some $0.8 \times 10^{11} \mathrm{~m}^{-3}$ occurs in the background density at about $73.5^{\circ} \mathrm{N}$ in the 40 min between the top and bottom panels of Fig. 8. A simple calculation shows that increased chemical recombination rates, for an ion temperature of $2000 \mathrm{~K}$ and a velocity of $1.2 \mathrm{~km} \mathrm{~s}^{-1}$ (Rodger et al., 1992) can result in a depletion of this magnitude on such a time scale, though in practice the actual situation was undoubtedly more complex.

\section{Discussion and conclusions}

The work concerns the interpretation of ionospheric signatures of equatorial reconnection under sunlit summer conditions. Emphasis has been placed on the gross behaviour of the plasma in response to a trend in $B z$ over a period of more than an hour, rather than transient events on time scales of a few minutes. A study by McCrea et al. (submitted 2000) for wintertime observations of the large-scale response of the ionosphere to changes in IMF orientation is also presented in this issue. In the current study footprints in the F region plasma, consistent with equatorial reconnection during a period of increasingly negative $B z$, have been identified by the EISCAT ESR and mainland radars, radio tomography, and the CUTLASS radar. In the enforced absence of measurements of optical emissions during the summer daytime, the interpretation has relied on DMSP particle data. However, it can be noted that Berry et al. (1999) have already linked DMSP measurements of particle fluxes and spectra to discrete structures in the ionospheric plasma in the post-noon sector imaged by radio tomography.

During the course of observations the IMF conditions were such that the field-of-view of the ESR radar changed from being on closed geomagnetic field lines with the signature of ion dispersion completely to the north, to being on open field-lines. It might be expected that a signature of the dispersion could be found in the ESR measurements, as the region moved equatorward through the field-of-view. For example, it is possible that an increase in peak height might be observed due to the most energetic particles coming first into the field-ofview followed by the slower particles in the dispersion tail. In general, inspection of the ESR measurements within the precipitation shows evidence for many transient events, over time scales of minutes and much less than that of the general trend in the southward motion. The ongoing pulsed reconnection throughout the period comprised many individual events whose varying characteristics serve to mask any possible signature in the layer height of the slow progression of the reconnection region and the associated ion dispersion. However, it can be noted that in the later stages of the observations shown in Fig. 6 the mapping of the reconnection site moved south of the field-of-view. Consistent with this motion is an increase in the height of the contours of the bottomside electron density and the topside electron temperature after about 0930 UT. The ESR results shown in Fig. 6 are in broad qualitative agreement with the predicted signatures of pulsed reconnection modelled by Davis and Lockwood (1996). In addition, the sequence of reconnection events suggested here is in accord with the meridian scanning photometer results of Sandholt et al. (1992), who showed that the $630.0 \mathrm{~nm}$ luminosity was characterised by a series of poleward-moving auroral forms representing the signatures of ongoing reconnection around midday in winter when such observations were possible. Comment should be made on the discrepancy between the electron densities measured by the ESR and the 
EISCAT radars, with the former being greater by some $70 \%$ for a common observing volume. Confirmation that it is the ESR densities that are high is obtained by comparison with the tomographic image. It has not proved possible to check the calibration of the ESR radar in this case as no observations are available from the ionosonde at Longyearbyen for the period under study. However, the absolute values of the electron densities are of little concern to the work presented here.

Unlike the investigation by Walker et al. (1998), the current study did not provide evidence for signatures in the ionospheric $\mathrm{E}$ region relating to the reconnection process. The operating modes of the radars were not designed for $\mathrm{E}$ layer studies, but there was little indication of the elevated electron temperatures extending down to the lowest altitudes. This absence of E region effects is not surprising within the general cusp region where the incoming particles are generally of low energy, and indeed in the present observations DMSP measured only soft-electron precipitation. These results are in accord with the modelling work of Millward et al. (1999) who predicted that ion precipitation into the cusp region produced ionisation at heights in the vicinity of the F1 ledge, with the plasma production due to softelectron precipitation maximising near the F2 peak.

The most striking ionospheric signature of the dispersion region in the present study was found in the electron temperatures measured by the mainland EISCAT radar that is attributed to energy deposition of the incoming precipitation (Nilsson et al., 1994). The progress of the reconnection footprint was marked by an abrupt equatorward edge with a tail of elevated, but decreasing, temperatures extending to the north. Figure 4 indicates good general agreement between the motion of the southern boundary of this region of increased electron temperature and the equatorward edge of the dispersion signatures seen at the different universal times by the DMSP satellites. The temperature boundary appears to be indicative of the position of the footprint of the reconnection site. It appears that this may represent a signature of use in identifying the separatrix between the open and closed magnetic fieldlines. Indeed it may be that a detailed investigation of the slope of such a boundary under steady southward IMF conditions, could mark the inclination of the newly opened magnetic field-lines. A possible study could be one reminiscent to that carried out by Jones et al. (1997), who used localised signatures of discrete soft precipitation to measure the inclination of the geomagnetic field above EISCAT.

The localised band of increased ion temperatures was found to be just to the south of the electron temperature boundary. These elevated ion temperatures result from frictional heating in the high plasma drift velocities in the sunward return flow of the afternoon cell, resulting in the formation of a density trough due to an increased recombination rate. Previous investigations have also reported a high-latitude dayside trough consistent in position with the return flow (Whalen, 1989; Pryse et al., 1998) though in these studies it was suggested that the trough resulted from low-density plasma, that had been circulating on flux-tubes in the night side, being carried in the sunward return flow into the dayside ionosphere. However, in the present case there is clear evidence to indicate a local formation mechanism for this highlatitude dayside trough as the plasma is eroded in a latitudinally confined region of ion frictional heating.

Central to the investigation were signatures of incoming ion flux along newly opened field-lines that were being swept antisunward. The DMSP passes showed a region of precipitation extending over about two degrees in latitude with an energy dispersion signature. The spatial distribution of ionospheric plasma measured by radio tomography showed an enhancement in the $\mathrm{F}$ layer with a sharp equatorward edge that was also some two degrees in latitudinal extent and that mapped to the region of ion dispersion. Significantly elevated electron temperatures in the topside ionosphere measured by the EISCAT mainland radar were also attributed to the effect of the incoming precipitation. The asymmetry in the latitudinal distribution, with an abrupt low-latitude edge and a diffuse northern extremity to the enhanced temperatures, supported the dispersion interpretation. It is possible that the sharp temperature transition at the equatorward edge may be an identifier in the ionosphere of the boundary between open and closed magnetic field lines. A narrow latitudinally localised enhancement in ion temperature was observed by the EISCAT radar just south of the limit of the region of elevated electron temperatures resulting in a density trough formed by frictional heating.

Acknowledgements. Financial support for the project has been provided by the UK Particle Physics and Astronomy Research Council under grant PPA/G/S/1997/00269. The assistance of the University of Tromsø, UNIS Longyearbyen and the Norwegian Polar Research Institute at Ny Ảlesund in the tomographic measurements is gratefully acknowledged. EISCAT is an international facility supported by the national science councils of Finland, France, Germany, Japan, Norway, Sweden and the United Kingdom. The DMSP data were provided by F. Rich at AFRL, Hanscom, USA. The CUTLASS radar is a UK national facility funded by the Particle Physics and Astronomy Research Council; the data used here have been supplied by T. Yeoman. The ACE data were obtained from the CDAWeb, NASA.

Topical Editor M. Lester thanks S. W. H. Cowley for his help in evaluating this paper.

\section{References}

Berry, S. T., L. Kersley, J. Moen, and W. F. Denig, Ionospheric signatures of magnetospheric boundaries in the post-noon sector, Ann. Geophysicae, 18, 74-80, 2000.

Cowley, S. W. H., Excitation of flow in the Earth's magnetosphereionosphere system: observations by incoherent scatter radar, in Polar cap boundary phenomena, Eds. J. Moen et al., NATO Advanced Study Institute Series, Kluwer, Dordrecht, The Netherlands, 509, 127-140, 1998.

Cowley, S. W. H., J. P. Morelli, and M. Lockwood, Dependence of convective flows and particle precipitation in the high-latitude dayside ionosphere on the $\mathrm{X}$ and $\mathrm{Y}$ components of the interplanetary magnetic field, J. Geophys. Res., 96, 5557-5564, 1991.

Davis, C. J., and M. Lockwood, Predicted signatures of pulsed reconnection in ESR data, Ann. Geophysicae, 14, 1246-1256, 1996. 
Dungey, J. W., Interplanetary magnetic field and the auroral zones, Phys. Rev. Lett., 6, 47-48, 1961.

Jones, D. G., I. K. Walker, and L. Kersley, Structure of the poleward wall of the trough and the inclination of the geomagnetic field above the EISCAT radar, Ann. Geophysicae, 15, 740-746, 1997.

Lockwood, M., P. E. Sandholt, S. W. H. Cowley, and T. Oguti, Interplanetary magnetic field control of dayside auroral activity and the transfer of momentum across the dayside magnetopause, Planet. Space Sci., 37, 1347-1365, 1989.

McCrea, I. W., M. Lockwood, J. Moen, F. Pitout, P. Eglitis, A. D. Aylward, J. C. Cerisier, A. Thorolfsson, and S. E. Milan, ESR and EISCAT observations of the response of the cusp and cleft to IMF orientation changes, Ann. Geophysicae, 18, 10091026, 2000.

Millward, G. H., R. J. Moffett, H. F. Balmforth, and A. S. Rodger, Modelling the ionospheric effects of ion and electron precipitation in the cusp, J. Geophys. Res., 104, 24 603-24 612, 1999.

Newell, P. T., and C.-I. Meng, Cusp low-energy ion cutoffs: a survey and implications for merging, J. Geophys. Res., 100, $21943-21951,1995$.

Nilsson, H., S. Kirkwood, L. Eliasson, O. Norberg, J. Clemmons, and M. Boehm, The ionospheric signature of the cusp: a case study using Freja and the Sondrestrom radar, Geophys. Res. Lett., 21, 1923-1926, 1994.

Pryse, S. E., L. Kersley, M. J. Williams, and I. K. Walker, The spatial structure of the dayside ionospheric trough, Ann. Geophysicae, 16, 1169-1179, 1998.

Pryse, S. E., A. M. Smith, J. Moen, and D. A. Lorentzen, Footprints of lobe reconnection observed in ionospheric electron density under steady northward IMF, Geophys. Res. Lett., 26, 25-28, 1999.
Pryse, S. E., A. M. Smith, L. Kersley, I. K. Walker, C. N. Mitchell, J. Moen, and R. W. Smith, Multi-instrument probing of the polar ionosphere under steady northward IMF, Ann. Geophysicae, 18, 90-98, 2000.

Reiff, P. H., and J. L. Burch, IMF $B y$-dependent plasma flow and Birkeland currents in the dayside magnetosphere 2. A global model for northward and southward IMF, J. Geophys. Res., 90, 1595-1609, 1985.

Rodger, A. S., R. J. Moffett, and S. Quegan, The role of ion drift in the formation of ionisation troughs in the mid- and highlatitude ionosphere - a review, J. Atmos. Terr. Phys., 54, 1-30, 1992.

Rosenbauer, H., H. Grunwaldt, M. D. Montgomery, G. Paschmann, and N. Skopke, HEOS-2 plasma observations in the distant polar magnetosphere: the plasma mantle, J. Geophys. Res., 80, 2723-2737, 1975.

Sandholt, P. E., M. Lockwood, W. F. Denig, R. E. Elphic, and S. Leontjev, Dynamical auroral structure in the vicinity of the polar cusp: multipoint observations during southward and northward IMF, Ann. Geophysicae, 10, 483-497, 1992.

Sandholt, P. E., C. J. Farrugia, J. Moen, Ø. Noraberg, B. Lybekk, T. Sten, and T.L. Hansen, A classification of dayside auroral forms and activities as a function of IMF orientation, J. Geophys. Res., 103, 23 325-23 345, 1998.

Walker, I. K., J. Moen, C. N. Mitchell, L. Kersley, and P. E. Sandholt, Ionospheric effects of magnetopause reconnection observed using ionospheric tomography, Geophys. Res. Lett., 25, 293-296, 1998.

Whalen, J. A., The daytime F-layer trough and its relation to ionospheric-magnetospheric convection, J. Geophys, Res., 94, 17 169-17 184, 1989. 